\title{
Medical Management of Non-Progressive Periorbital Necrotizing Fasciitis
}

\author{
Ziya Ayhan, Aylin Yaman, Meltem Soylev Bajiin \\ Department of Ophthalmology, Dokuz Eylul University Faculty of Medicine, Izmir, Turkey
}

\begin{abstract}
Necrotizing fasciitis (NF) is a serious soft tissue infection with a significant fatality rate. Although the cause may be polymicrobial, the most common microbial agents are Streptococcus pyogenes and Staphylococcus aureus. Early recognition and aggressive surgical debridement are usually required to prevent the rapid spread of infection. Presently described is a case of NF of the eyelids in a patient who had a good response with intravenous antibiotic therapy.

Keywords: Medical treatment, necrotizing fasciitis, non-progressive.
\end{abstract}

\section{Introduction}

Necrotizing fasciitis (NF) is a rapidly progressive and serious infection of the subcutaneous tissue and superficial fascia with secondary necrosis of the overlying skin. Although periorbital NF is uncommon, as a result of an excellent blood supply, it can result in visual loss or even death. Early recognition and initiation of treatment is essential to decrease morbidity and mortality (I). Surgical debridement and highdose intravenous antibiotic therapy are usually combined in the treatment of this phenomenon. Though antibiotics may not reach the infected area due to thrombosis, a successful outcome may be obtained in mild cases with antibiotic therapy alone (2).

Presently described is a patient who was treated and cured with intravenous antibiotic therapy and without the need for debridement.

\section{Case Report}

A 78-year-old woman presented at the clinic with bilateral eyelid swelling, blackened areas of the surrounding periorbital skin, and mild pain. She did not have any history of trauma. She described a history of the right eye and surrounding area becoming red and swollen first, followed by a similar progression on the left side the next day. Her past medical and ocular history was unremarkable. On examination, black necrotic areas in the periorbital region with mild swelling and redness were observed bilaterally (Fig. I). The patient's visual acuity was 2/10 in both eyes. A bilateral grade 3 nuclear cataract was detected in both eyes with slit-lamp examination. Intraocular pressure was measured as $14 \mathrm{mmHg}$, bilaterally. The optic disc and macula were normal in both eyes on dilated fundus examination. There was no orbital involvement. Relative afferent pupillary defect, diplopia, or gaze palsy was not detected. At the time of examination, the body temperature of the patient was $38.5^{\circ} \mathrm{C}$ and the patient was oriented. Blood analysis revealed mild leukocytosis (total white cell count: $10.5 \times 10^{3} / \mu \mathrm{L}$ with $90 \%$ neutrophilia). The C-reactive protein (CRP) level was $503 \mathrm{mg} / \mathrm{mL}$, and the erythrocyte sedimentation rate (ESR) was $>110 \mathrm{~mm} /$ hour. The serum urea and creatinine levels were moderately elevated. After consultation with the departments of infectious diseases, otolaryngology, and plastic surgery, a clinical diagnosis of periorbital NF was confirmed. Intravenous meropenem I g every 8 hours, vancomycin 1.5 g every 12

Address for correspondence: Ziya Ayhan, MD. Department of Ophthalmology, Dokuz Eylul University

Faculty Of Medicine, Izmir, Turkey

Phone: +90 2324123066 E-mail: zyayhan@yahoo.com

Submitted Date: November 03, 2017 Accepted Date: November 19, 2017 Available Online Date: March 30, 2018

${ }^{\circ}$ Copyright 2018 by Beyoglu Eye Training and Research Hospital - Available online at www.beyoglueye.com 


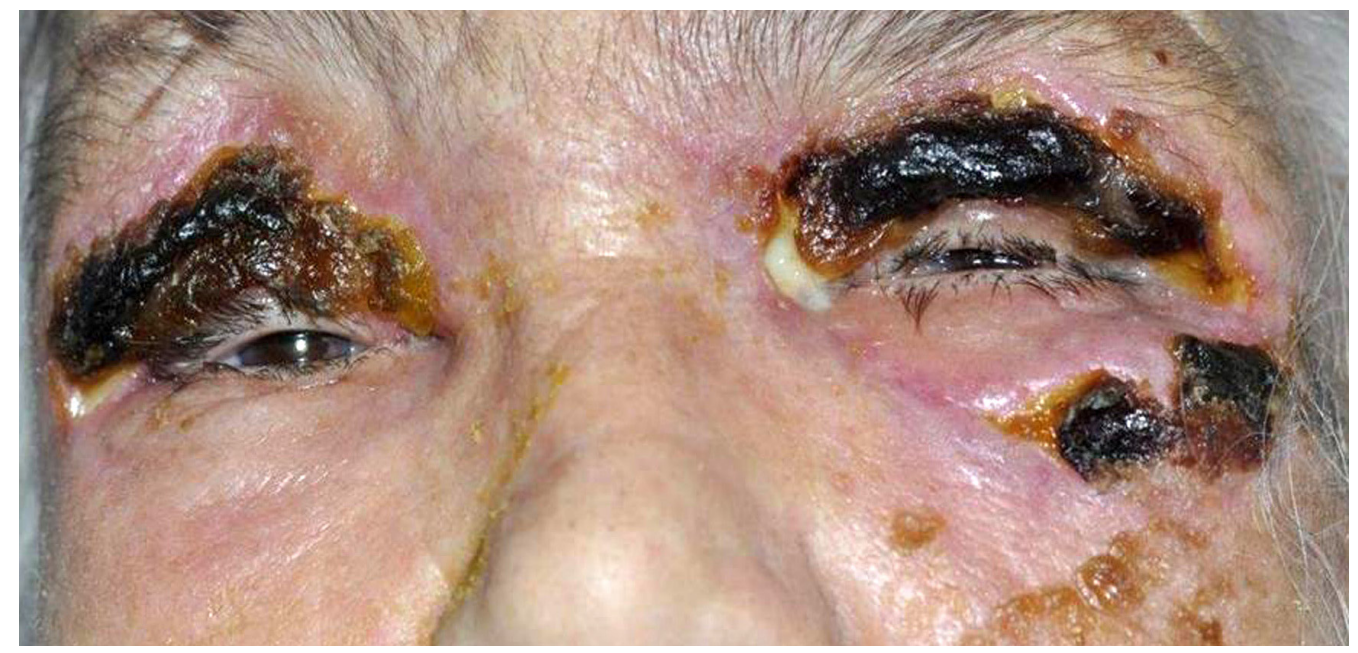

Figure I. A photo of the patient taken at presentation. Necrotic areas are evident on both upper eyelids.

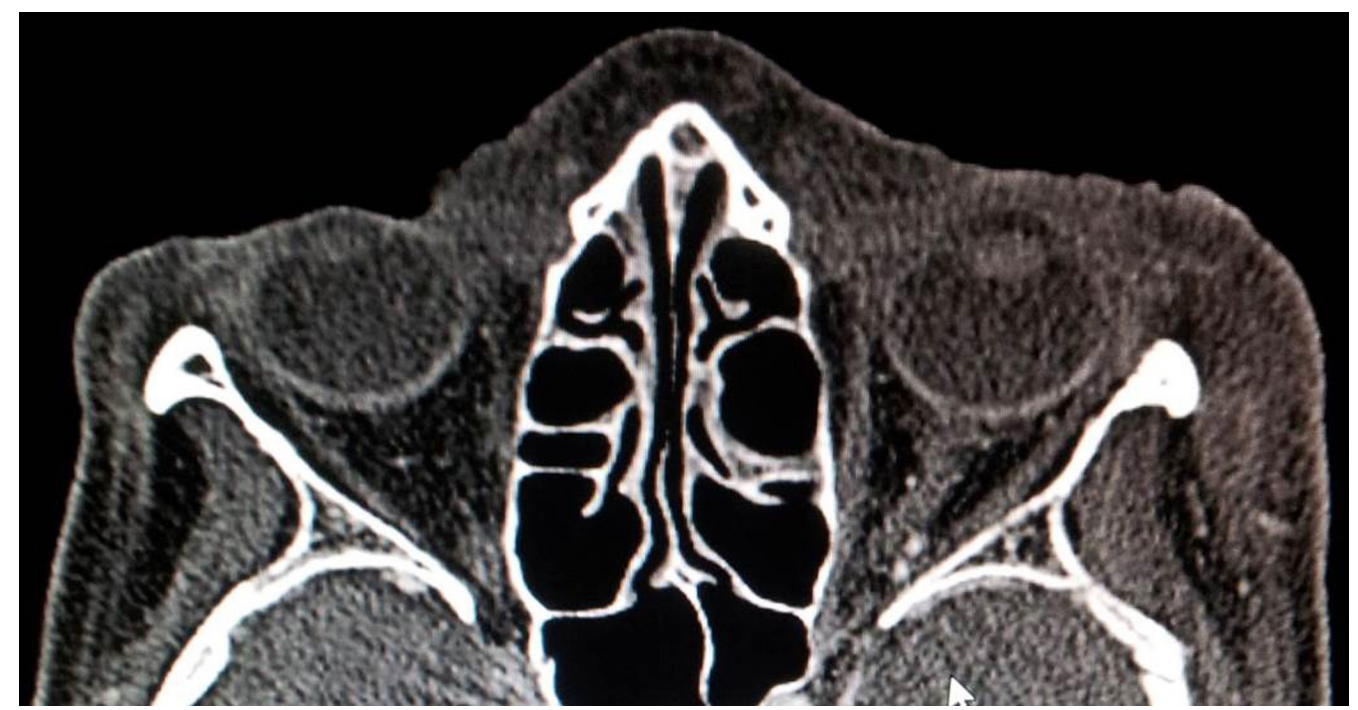

Figure 2. Computed tomography scans indicated soft tissue edema in the bilateral preseptal subcutaneous tissue.

hours, and clindamycin $600 \mathrm{mg}$ every 8 hours was initiated as empirical treatment. An emergency computed tomography scan revealed bilateral soft tissue inflammation anterior to the orbital septum (Fig. 2). Analysis of a biopsy specimen indicated the presence of squamous epithelial cells among widespread neutrophils and eosinophiles. Mucormycosis and herpes zoster were not detected. No organism was identified in a wound and blood culture. The patient's temperature was $37.5^{\circ} \mathrm{C}$, the CRP level was $15 \mathrm{I} \mathrm{mg} / \mathrm{mL}$, and the ESR was $75 \mathrm{~mm} /$ hour 3 weeks after the initiation of empirical treatment. The patient was followed up for the necrotic tissue in the periorbital area but no surgical debridement was performed as a result of the good response to medical therapy. After improvement of clinical signs, the patient was released from the hospital with oral amoxicillin-clavulanate antibiotic therapy (Fig. 3).

\section{Discussion}

NF usually develops secondary to trauma or surgery (I, 3-5). Some predisposing factors, such as immunosuppression, malignancy, diabetes mellitus, and alcoholism can cause this phenomenon. Periorbital NF has been reported after trauma and surgical operations, such as blepharoplasty and dacryocystorhinostomy (3-5). Suner et al. (4) described a case of a 74-year-old woman with a history of type II diabetes mellitus who underwent bilateral upper eyelid blepharoplasty. Postoperatively, she developed a fever, grayish discoloration of the skin, violaceous bullae, and palsy of the right facial nerve. NF was diagnosed and treated with intravenous antibiotics, debridement of the necrotic tissue, and hyperbaric oxygen therapy. There was no predisposing factor like trauma, a history of surgery, or a concomitant systemic disorder in our 


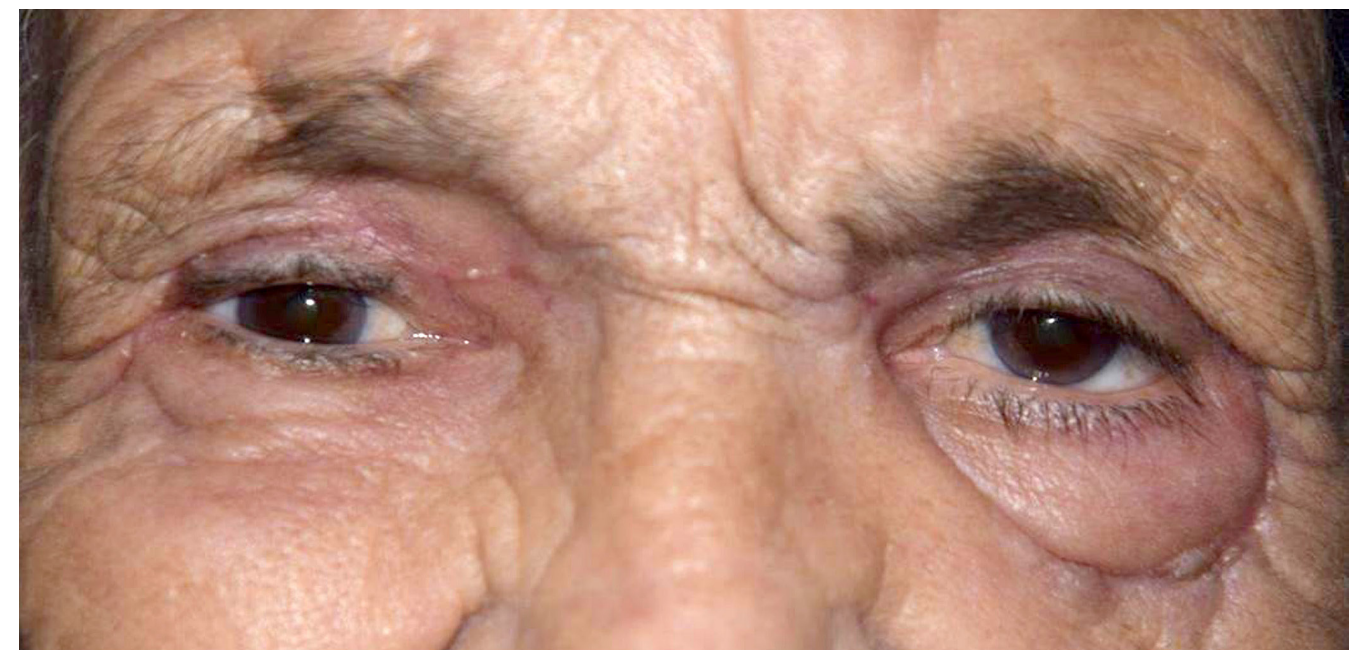

Figure 3. A photo of the patient taken 2 months after the initiation of treatment. The necrotic areas healed with intravenous antibiotic treatment and debridement was not necessary.

case. The diagnosis of periorbital NF was made clinically. The initial clinical appearance of periorbital NF is usually edema and redness in the region, resembling preseptal cellulitis or erysipelas. After the appearance of the initial signs, the skin then becomes more dusky and grey-blue in color, eventually becoming blackish with a crust forming as a result of the progressive thrombosis of blood vessels (I). Computed tomography and magnetic resonance imaging help in making an early diagnosis and also to differentiate NF from orbital cellulitis and mucormycosis. Imaging scans can be used to guide surgical debridement (6). The most commonly observed causative microorganisms are Streptococcus pyogenes, Staphylococcus aureus, or a combination of facultative and anaerobic organisms, including Group C, G, H Streptococci, Haemophilus influenzae type B, Bacteroides and Clostridia (I). In our case, the causative microorganism could not be identified, despite repeated microbiological analyses. Early recognition and initiation of intravenous high-dose antibiotics combined with tissue debridement helps to decrease morbidity and mortality. Mild cases may respond to antibiotic therapy alone, as in the present case. The standard initial antibiotic therapy consists of a combination of beta-lactam antibiotics and clindamycin, since multiple microorganisms may be responsible. Surgical debridement decreases the bacterial load and helps with the transmission of antibiotics through the infected areal. Repeated debridement may be necessary if the response to treatment is slow (6). The role of hyperbaric oxygen therapy in the management of NF is controversial. It may help to limit ischemic tissue. Intravenous gamma globulins are also recommended in the management of NF (7). No surgical debridement was undertaken in our case due to the good response to medical therapy. The major morbidity risk is orbital spread and loss of vision. Cos- metic disfigurement and functional problems of the eyelids may also be seen $(8,9)$. Raja et al. (8) reported a case of NF initially misdiagnosed as traumatic pre-septal cellulitis following self-puncture of a hordeolum externum in which resistance to aggressive antibiotic therapy resulted in the loss of the lower eyelid. Mortality from periorbital NF is typically caused by the spread of infection to the neck and thorax (10).

Early recognition and effective treatment are the most important factors to reduce the risk of morbidity and mortality. Although surgical debridement and high-dose intravenous antibiotic therapy are usually essential in cases of periorbital NF, a successful outcome may be obtained in mild cases with antibiotic therapy alone, as in our case.

\section{Disclosures}

Informed consent: Written informed consent was obtained from the patient for the publication of the case report and the accompanying images.

Peer-review: Externally peer-reviewed.

Conflict of Interest: None declared.

Authorship Contributions: Involved in design and conduct of the study (ZA, AY, MSB); preparation and review of the study (ZA); data collection (ZA).

\section{References}

I. Amrith S, Hosdurga Pai V, Ling WW. Periorbital necrotizing fasciitis - a review. Acta Ophthalmol 2013;91:596-603. [CrossRef]

2. Luksich JA, Holds JB, Hartstein ME. Conservative management of necrotizing fasciitis of the eyelids. Ophthalmology 2002;109:21 18-22. [CrossRef]

3. Balaggan KS, Goolamali SI. Periorbital necrotising fasciitis after minor trauma. Graefes Arch Clin Exp Ophthalmol 
2006;244:268-70. [CrossRef]

4. Suñer IJ, Meldrum ML, Johnson TE, Tse DT. Necrotizing fasciitis after cosmetic blepharoplasty. Am J Ophthalmol 1999; 128:367-8.

5. Hirschbein MJ, LaBorwit SE, Karesh JW. Streptococcal necrotizing fasciitis complicating a conjunctival dacryocystorhinostomy. Ophthal Plast Reconstr Surg 1998;|4:28I-5. [CrossRef]

6. Saldana M, Gupta D, Khandwala M, Weir R, Beigi B. Periorbital necrotizing fasciitis: outcomes using a CT-guided surgical debridement approach. Eur J Ophthalmol 2010;20:209-14. [CrossRef]

7. Seal DV. Necrotizing fasciitis. Curr Opin Infect Dis 200 I; I4:127-
32. [CrossRef]

8. Raja V, Job R, Hubbard A, Moriarty B. Periorbital necrotising fasciitis: delay in diagnosis results in loss of lower eyelid. Int Ophthalmol 2008;28:67-9. [CrossRef]

9. Prendiville KJ, Bath PE. Lateral cantholysis and eyelid necrosis secondary to Pseudomonas aeruginosa. Ann Ophthalmol 1988;20:193-5.

10. Puri P, Innes JR. Necrotising fasciitis of the orbit: early recognition and treatment a key to success. Eur J Ophthalmol 200 I; I I:I80-2. [CrossRef] 